\title{
RESEÑ̃A
}

\section{SOBRE EL PROBLEMA DE LA EDUCACIÓN EN KANT Una lectura del Tratado de Pedagogía}

\begin{abstract}
La presente reseña sobre la obra pedagógica de Kant se apoya en dos traducciones al español: Kant, I. "Sobre pedagogía". En: Luzuriaga, L. Kant, Pestalozzi y Goethe. Sobre educación. Madrid: Daniel Jorro, Editor, 1911. Y la que se citará en este artículo, Kant, I. Tratado de Pedagogía. Traducción de Carlos Eduardo Maldonado. Bogotá: Ediciones Rosaristas, 1985.
\end{abstract}

\section{INTRODUCCIÓN}

Por su condición de profesor de filosofía Kant debía en la universidad, desempeñar cátedras de pedagogía, así como otros recordados filósofos (Hegel, Schleiermacher y Fichte entre otros). Tal tarea lo llevó a ocuparse en sus escritos de la teoría de la educación. Reflexiones que fueron recogidas de sus exposiciones por un discípulo suyo y luego publicadas, antes de su muerte(1803), con el título original: Uber Pedagogik'.

Se presenta esta obra, en primer lugar, contextualizando el siglo XVIII, también llamado el siglo de las Luces, de la Razón o época de la filosofía, en el cual se inspira y se deriva su teoría educativa, y quizá uno de los momentos históricos en que es vivido más apasionadamente el problema educativo(I), y en segundo lugar, acercándonos al Tratado de Pedagogía en donde se manifiestan sus reflexiones sobre la educación, en que consiste y lo que comprende asumirla como proyecto de la especie humana(II).

\section{I}

\section{La época ilustrada de Kant}

Filosofía y educación, relación que a través de la historia ha jugado un papel decisivo para la existencia de la sociedad humana. Relación que no ha sufrido complicaciones desde la época griega (con Platón y Aristóteles) pasando por la ilustración europea (Roussean, Kant, Hegel) hasta las reflexiones de pensadores contemporáneos como Gadamer, Adorno, Morin y Dewey entre otros.

Las reflexiones educativas de Kant escritas en su bello Tratado de Pedagogía se inscriben en la época ilustrada, de la cual es uno de los arquitectos principales y exponente máximo. La llustración como proyecto humanizador y liberador de la especie humana, es a su vez una tarea educativa consistente en desarrollar en el hombre la fuerza uni- versal de la Razón. ¿En qué consiste esta época histórica y modo de ser llamado ilustración o siglo de las luces?

La llustración pone la Razón en el centro de las relaciones humanas y por supuesto como el puente para dar explicación de lo humano y de sus limites en términos también racionales. A la razón se le consideró en el siglo XVIII, la fuerza homogénea y unitariamente informadora ${ }^{1}$, que en su despliegue ofrece progreso y felicidad humana indefinida. Fuerza que se presenta como razón crítica, liberadora e interesada y como razón autónoma². Razón Crítica ante todo dogmatismo sagrado o legislativo que se quiera autoproclamar como fundamento y razón última de explicación. Razón Liberadora e Interesada en desarrollar el conocimiento de la teoría

\footnotetext{
${ }^{1}$ Cassirer, Ernst. Filosofía de la Ilustración. Bogotá: FCE, 1994, pág. 20.

${ }^{2}$ Cortina, A. Ética Mínima, Madrid: Tecnos, 1994, pág. 208ss.
} 
ilustrada que es decididamente crítico y liberador mediante la reflexión, para lograr su etapa más alta que es el progreso en la autonomía de los individuos ${ }^{3}$ (Razón Autónoma), con la sustitución de toda autoridad (religiosa y legislativa) y tradición como guías de la conducta humana. Ya Kant en su respuesta a la pregunta ¿Qué es la llustración? expresó que la razón es autónoma, tiene sus propias leyes:

"La llustración es la liberación del hombre de su culpable incapacidad. La incapacidad significa la imposibilidad de servirse de su inteligencia sin la guía de otro. Esta incapacidad es culpable porque su causa no reside en la falta de inteligencia sino de decisión y valor para servirse por sí mismo de ella sin la tutela de otro. ¡Sapere aude! !Ten el valor de servirte de tu propia razón! He aquí el lema de la llustración"4.

La fuerza de la razón también abre la entrada al conocimiento de la naturaleza como espacio abierto y múltiple de interpretaciones, como horizonte del saber, del abarcar la realidad. Con ello se diluye la forma estática del imaginario antiguo y medieval del mundo, cesa la idea de un cosmos susceptible del ser abarcado en su conjunto. El conocer la naturaleza para el hombre ilustrado se convierte en su posibilidad de conocerse, el medio dentro del cual lleva a cabo su propio conocimiento ${ }^{5}$. $Y$ es así, como se ha podido afirmar que "la reflexión sobre la edu-

\footnotetext{
${ }^{3}$ Habermas, J. "Dogmatismo, razón y decisión". En: Teoría y praxis. Ensayos de Filosofía Social, Madrid: Tecnos, 1994, pág. 288.

${ }^{4}$ Kant, E. Filosofía de la historia. Bogotá: F.C.E, 1994, pág. 25.

${ }^{5}$ Cassirer, E. Filosofía de la llustración. Bogotá: FCE, 1994, pág. 54.
}

cación no puede prescindir del concepto de naturaleza dado que este constituye algo así como su antagonista necesario". La educación no puede perderla de vista como su punto de referencia. Y Kant escribió sobre esta línea de la naturale$\mathrm{za}^{7}$ sus reflexiones pedagógicas, influenciado por sus contemporáneos Rousseau y Pestalozzi. Aunque Kant tiene un poco más allá al precisar que en la educación del hombre se debe hacer violencia a la animalidad, estableciendo rupturas con la mera naturaleza ${ }^{8}$. El hombre es la única criatura que requiere educación -afirma Kant-por ello la disciplina y la instrucción juntamente con la cultura convierte el estado de animalidad en el de humanidad. $Y$ añade: "la especie humana debe extraer poco a poco, por sí misma, y con su propio esfuerzo, todas las cualidades naturales de la humanidad"9.

\footnotetext{
${ }^{6}$ Reboulo, O. "La Philosophie de l' educación”. París: 1976, pág. 43. En: Hegel, F. Escritos pedagógicos. Traducción de Ginzo Arsenio, México: FCE, 1998, pág. 33. ${ }^{7}$ Aquí Kant escribe bajo el espíritu ilustrado, del cual es su mayor exponente, pues la educación era un problema que se asumía recurriendo al modelo de la naturaleza. Pestalozzi en "Las Veladas de un Ermitaño" ya lo confirmaba: "Orientación de la vida, destino del hombre, eres el libro de la Naturaleza. En ti está contenida la fuerza y el orden de esta sabia conductora; la educación escolar que no se construya con este fundamento, va descaminada". Pestalozzi, J.E. "Las veladas de un ermitaño". En: Luzuriaga, L. Sobre educación. Kant, Pestalozzi y Goethe. Madrid: Daniel Jorro, Editor, 1911, pág. 117.

${ }^{8}$ La filosofía de Kant esta presidida por una indubitable intención educativa ya que la ilustración como una tarea educativa, posibilita al hombre distanciarse de la naturaleza y crear un mundo humano en el que ya no gobiernan las leyes determinadas por la naturaleza sino la moralidad surgida de la libertad.

${ }^{9}$ Kant, I. Tratado de pedagogía, Bogotá: Ediciones Rosaristas, 1985, pág. 1.
}

Una vez realizada la tarea de la ilustración de liberar a la humanidad de prejuicios y dogmatismos, los individuos podrían convertirse en sujetos autónomos de su propio desarrollo por medio de la fuerza llamada Razón. Facultad a la que Kant asigna un poder práctico. En consecuencia, la tarea práctica de la llustración desde Kant, es una tarea educativa: formar a toda persona sobre la fuerza universal de la razón para la construcción de una sociedad que satisfaga sus aspiraciones y necesidades.

En este contexto de la época ilustrada tenemos una ligera idea de su tarea educativa. Tarea que ayudó decididamente a desarrollar y definir las diferentes ideas pedagógicas del siglo XVIII, las cuales se pueden reducir a las siguientes:

a) Creencia en el poder absoluto de la razón y en la educación como encargada de conducirla.

b) El reconocimiento de la naturaleza y de las leyes naturales en el universo y la sociedad, abriendo paso al naturalismo pedagógico.

c) Secularización de la educación, disminuyendo el poder eclesiástico y fortaleciendo el poder del Estado.

d) La aspiración a la libertad, sustituyendo toda autoridad religiosa y legislativa, así como toda tradición social, surge entonces el individualismo como principio educativo.

e) Un espíritu progresista, positivo y optimista en la vida desarrollado por medio de la educación del ser humano.

Siempre se educa teniendo como proyecto un estado mejor, hacer del mundo un lugar mejor. Por eso Kant define la educación como una práctica que perfecciona cada genera- 
ción, "un arte cuya aplicación debe ser perfeccionada por muchas generaciones"10, es algo propio de la especie humana educarse en lo racional.

\section{II}

Ahora bien, quiero acercarme al Tratado de Pedagogía de Kant, en donde se resumen sus reflexiones educativas, sistemáticamente y que junto con obras mayores como la Critica de la Razón Práctica y la Fundamentación de la Metafísica de las Costumbres, manifiesta la idea de perfectibilidad de la naturaleza humana y el papel de la educación. No es difícil reconocer, entonces, en su Tratado de Pedagogía de alguna manera, el proyecto intelectual fundamental de Kant: Sentar los fundamentos filosóficos de los principios universales de justificación racional, que pusiera de manifiesto la capacidad de verdad y objetividad racionales de todos los seres humanos.

\section{Sobre el concepto, papel e importancia de la educación en el hombre}

Kant comienza afirmando que el hombre es la única criatura que necesita Educación, exclusivamente por ella es que el hombre llega a ser hombre. Pero como el desarrollo de las disposiciones naturales en los hombres no se da por sí mismo, la educación se convierte en un arte cuya aplicación debe ser perfeccionada por muchas generaciones. El hombre debe extraer estas cualidades naturales, por sí mismo, guiado por la razón y por la interacción con otros seres de su misma especie. De aquí la importancia que una generación eduque a otra, pues nin-

10 Ibídem, pág. 5. gún individuo humano puede alcanzar sólo su destino. Cada generación, prevista de los conocimientos de las anteriores, puede dar una educación que desarrolle cada vez más las disposiciones naturales de los hombres de un modo equilibrado y conforme a sus fines, $y$, de este modo, conducir a toda la especie humana a su destino. Por eso un principio pedagógico que debería considerarse siempre, es el de que no se deba educar a partir del estado presente de la especie humana, sino a partir de un posible mejor estado del futuro; es decir, a partir de la idea de la humanidad y de su destino.

Como la educación es un arte, su origen y su desarrollo, o es mecánico, o es razonado; pero como todo arte mecánico esta sometido a las circunstancias dadas, sin plan, con errores y carencias, el arte de la educación o pedagogía debe ser racional a fin de que la naturaleza humana pueda desarrollarse y alcanzar su destino, y a fin de que el arte de la educación se transforme en ciencia, pues de lo contrario, no constituiría un esfuerzo continuo sobre la idea correcta de la educación de la especie humana y su destino en términos racionales, ni tampoco haría posible la comunicación entre generaciones.

En suma para Kant, en la educación se encuentra el gran secreto de la perfección de la naturaleza humana. Para él, es cautivante pensar que la naturaleza humana puede llegar a desarrollarse cada vez más mediante la educación y que a ésta se le puede dar la forma por la cual la humanidad puede ser medida. A pesar que educar sea un problema con dificultades, el esbozo de una teoría de la educación es un noble ideal, y en nada nos perjudi- ca aunque no estemos en capacidad de realizarlo todavía. Por ello, la educación debe lograr disciplinar ${ }^{11}$ a los hombres para la domesticación del salvajismo; cultivar a los hombres por medio de la instrucción y la enseñanza para desarrollar la aptitud o la habilidad para todos los fines posibles; hacer prudentes a los hombres para vivir en sociedad y velar por la moralización ${ }^{12}$ de los hombres para la elección de fines buenos, aceptados y aprobados por todos y cada uno de los hombres ${ }^{13}$.

Ahora bien, para Kant la pedagogía o ciencia de la educación es a la vez física y práctica. La primera consiste propiamente en los cuidados que necesita el hombre de alimentación por parte de los padres y de las criadas; y la segunda, la educación práctica o moral es la educación para la libertad y para construcción de la personalidad moral. Desde esta comprensión de la educación como física y práctica, Kant comienza a desarrollar los

\footnotetext{
${ }^{11}$ En Kant, la disciplina es la categoría que hace posible la humanidad, la condición a priori para que el ser humano pueda llegar a serlo verdaderamente. A lo que añade: "De aquí, pues, que el hombre se deba acostumbrar desde muy joven a someterse a los preceptos de la razón. Cuando en la juventud se le permite hacer su voluntad y no se le contraría en nada, conserva un cierto salvajismo el resto de la vida". Ibídem, pág. 2.

${ }^{12}$ No debe extrañar, que Kant señale en su Tratado de Pedagogía de las cuatro dimensiones que ha de promover la educación quede pendiente la moralización: "Nosotros vivimos en una época de disciplina, de cultura y de civilización, pero no todavía de moralización. Y cabe preguntarnos, si seriamos más felices en un estado primitivo sin toda la cultura actual". Ibídem, pág. 10. Al fin de cuentas, en su obra ldea de una historia universal en sentido cosmopolita (1784), constata que a pesar de ser culto en alto grado y civilizado hasta el exceso, al hombre le falta mucho para ser considerado moralizado.

${ }^{13}$ Ibídem, págs. 1-11.
} 
conceptos de autonomía y libertad importantes en su proyecto filosófico como problema exclusivamente educativos con preguntas como: ¿Cómo formar la libertad con restricciones, cómo fundamentar la moralidad en los niños? A lo que añade: "es preciso acostumbrar al estudiante a que su libertad se sujete a una restricción, $y$, al mismo tiempo, enseñarle a hacer un buen uso de ella, sin lo cual no sería más que una máquina"14. ¿ Para qué tenemos la razón? Para darle un uso práctico, así nos ha sido concedida como una "facultad práctica"15, en la cual se constituye la imagen moral del mundo. ¿Qué es la autonomía? "No elegir de otro modo sino de éste: que las máximas de la elección, en el querer mismo, sean al mismo tiempo incluidas como ley universal"16. Y define a la vez cómo la formación para la independencia y la autonomía racional ha de iniciarse desde los primeros cuidados al hombre.

\section{La Educación Física}

Saber en que consiste la educación desde el principio hasta el final, es indispensable para todo aquel que decida ser educador del ser humano desde la niñez como ayo o gobernante ${ }^{17}$, pues el desarrollo de la educación física debe seguir el principio regulador de la naturaleza.

\footnotetext{
${ }^{14}$ Ibídem, pág. 15.

${ }^{15}$ Kant, I. Fundamentación de la Metafísica de las Costumbres. México: Porrúa, pág, 23.

${ }^{16}$ Ibídem, pág. 52.

${ }^{17}$ Es razonable que en su condición de espíritu ilustrado, Kant recurra a la acción de los gobernantes -y aquí la figura de Federico el Grande toma una especial relevancia- a fin de que, en su afán de gloria, persigan el bien común y para que desarrollen campañas a favor de la ilustración.
}

Educación física como formación de las facultades propias del espíritu ha de lograrse por medio de: Primero, la cultura general de las facultades del espíritu, ésta se divide en:

a) Física: donde todo el aprendizaje descansa en el ejercicio y la disciplina del cuerpo, el control de los movimientos y el desarrollo de los sentidos. Esta formación física apunta sólo hacia la naturaleza ${ }^{18}$. Es pasiva. La primera y más importante regla, es, aquí, en la medida de lo posible, eludir toda clase de artefactos. Se debe evitar que la disciplina se torne esclavista. Aquí se cultivan a los hombres.

b) Moral: Esta apunta solamente hacia la libertad. Se basa ya no en la disciplina, sino sobre máximas. Es activa. Se trata, pues, aquí, de moralizar a los hombres.

Segundo, la cultura particular de las facultades del espíritu. Se trata del cultivo de las facultades menores (los sentidos, la imaginación, la memoria, la observación, y el ingenio) y superiores del entendimiento (entendimiento, juicio y razón).

Las facultades inferiores serán cultivadas, sólo en función de las superiores, por ejemplo, el ingenio, en

\footnotetext{
${ }^{18}$ Aunque esta cultura del alma o física apunte solamente hacia la naturaleza Kant se cuida de toda actitud finalista y en la posibilidad de pensar la libertad y la causalidad de la naturaleza desde un mismo punto de vista. A lo que añade: "Debemos hacer la distinción aquí entre naturaleza y libertad. Dar leyes a la libertad es totalmente diferente de formar la naturaleza. La naturaleza del cuerpo y la del alma están de acuerdo en que en su formación se busca detener la corrupción y en que el arte agrega algo tanto a la una, como a la otra". En: Kant, I. Tratado de Pedagogía, pág. 29.
}

función de la inteligencia; la imaginación, solo en provecho del entendimiento. La regla principal a seguir aquí es la de no cultivar ninguna facultad individual por sí misma, sino siempre en relación con todas las demás ${ }^{19}$.

\section{Cultura Física ${ }^{20}$}

En la formación del niño ha de evitarse el uso de ayudas artificiales para su normal crecimiento según los indicadores del desarrollo natural; por ello Kant sugiere eludir el uso de pañales, el mantener los niños muy abrigados, el mecer a los niños, el uso de andadores o caminadores y los corsés (en el caso de niños con defectos), bajo las siguientes razones:

- Hay que prevenir que el niño se acostumbre a ciertas cosas o prácticas, y no permitir que surja en el ningún hábito. Cuantos más hábitos tengan un hombre, tanto menos libre e independiente es.

- Todos estos mecanismos artificiales son tanto más funestos cuanto que atenta directamente contra el fin que se propone la naturaleza en los seres organizados y racionales, de acuerdo con el cual fin debe quedar la libertad suficiente para que el niño aprenda a servirse de sus propias fuerzas.

\footnotetext{
${ }^{19}$ Kant, I. Tratado de Pedagogía, pág. 31.

${ }^{20}$ Esta parte de su obra es significativa por la atención que le da al cuerpo del niño, en forma de consejos de vestimenta y de las ayudas externas al cuerpo natural, lo cual hace ver en Kant más que una orientación de tipo pedagógico una filosofía naturalista. Quienes desarrollaron pedagógica y didácticamente este pensamiento pediátrico, fueron Rousseau y Pestalozzi junto con su precursor John Locke.
} 
- Permitir al niño aprender espontáneamente, muchas cosas y más sólidamente ${ }^{21}$.

Esta es la primera y más importante regla a cumplir en los cuidados físicos o en la cultura física para no arruinar en el ser humano las destrezas naturales.

Ahora bien, como en toda cultura física se trata de cultivar a los hombres es conveniente formar la voluntad en el niño para prevenirle de malas costumbres y ejercitarle los sentidos, la imaginación, la memoria, la capacidad de observación y el ingenio.

En lo primero, se le educa de modo tal que no obtenga nada con sus gritos para que llegue a ser libre, amistoso y sincero. Para ello es indispensable que encuentre la resistencia y firmeza en sus educadores. No obstante, hay que evitar la disciplina hostigante, esclavizante, para no quebrantar su voluntad. Quebrantar la voluntad, produce un modo de pensar esclavizante, resistirla naturalmente produce docilidad. Desde temprana edad es de suma importancia que los niños aprendan a ocuparse en algo, pues el hombre requiere ocupación; incluso aquellas ocupaciones que exigen algún esfuerzo. $Y$ ¿dónde mejor que en la escuela debe cultivarse la afición al trabajo? La escuela es una cultura forzada. Es allí en donde se le ha de formar en el trabajo. La formación escolar debe ser para el niño trabajo. Es cierto que se debe dar un tiempo para el juego, pero también para el trabajo. La escuela en la formación de su espíritu ha de practicar en diferentes momentos

${ }^{21}$ KANT, I. Tratado de Pedagogía, págs. 22 y 23. ambos tipos de cultura (la escolar y la libre $)^{22}$

En lo segundo, es conveniente la ejercitación de los sentidos, en particular el de la vista en la apreciación correcta a distancia, del tamaño y la proporción de los objetos, y el de encontrar la posición de lugares a partir de los objetos dados, en donde el sol es de gran ayuda. De igual manera es necesario el cultivo del oído con el fin de que pueda saber si algo se encuentra lejos o cerca, y en qué lado se halla. En cuanto al cultivo de la imaginación ha de tenerse en cuenta que los niños tienen una imaginación extremadamente rica y que no requiere en absoluto ser ampliada ni extendida más, con la ayuda de cuentos. Ha de cuidarse de dejarla inactiva por completo. En cuanto la memoria se debe cultivar tempranamente y ejercitarse en cosas relacionadas con la vida real, mediante la retención de los nombres encontrados en los relatos, la lectura y la escritura y por medio del aprendizaje de los idiomas.

El ingenio ha de cultivarse al lado de la facultad de juicio. De lo contrario, produce puras tonterías. En lo que atiende a la capacidad de observación, base de la memoria, ha de fortalecerse en nuestro pensamiento para que en casos de flexibilidad no se deje guiar a donde quiera $^{23}$.

Pero como las facultades inferiores no tienen por sí solas ningún valor, v. gr: un hombre con mucha memoria e ingenio pero sin la facultad del juicio, o un hombre con imaginación pero sin entendimiento. Es por ello

\footnotetext{
22 Ibídem, págs. 30-31 y 38.

${ }^{23}$ Ibídem, págs, 32-33 y 35.
}

necesario, el cultivo de las facultades superiores como el entendimiento (conocimiento de lo universal), el juicio (aplicación de lo universal a lo particular) y la razón (la facultad de comprender la unión de lo universal con lo particular). En esta última reconocemos los principios, y en especial, los principios que se relacionan con el deber. En suma, de lo que se trata aquí es de hacerlas extraer de ellos mismos los conocimientos racionales y no tanto darles fundamentos de razón. Por ello, se ha de proceder en su formación a la manera socrática, es decir, se reflexiona según causas y efectos y no solamente se especule. Sé de uso de la razón en su facultad práctica propia de los niños que comprenden produciendo. De esto se desprende la gran relevancia del trabajo práctico para Kant, por ello sugiere comenzar el aprendizaje de los niños con la geografía, en la elaboración de los mapas y de figuras de animales y plantas que le dan vida a la geografía.

\section{Cultura Moral}

En esta parte kant comienza a desarrollar pedagógicamente lo que tiene que ver con la formación moral en los niños. Ella tiene que fundarse en las máximas de acción y no en los estímulos e intereses para actuar, de lo que se deduce el propósito de la formación moral: cimentar o fundar un carácter. Formación que tiene que ver con tres rasgos principales: la obediencia, esta es doble; en primer lugar, es acatamiento a la voluntad absoluta del director, y luego, a la voluntad reconocida como razonable y buena. La veracidad es otro rasgo principal en la fundación del carácter del niño. Es de las más esenciales. Por ello Kant insistía anteriormente en el desarrollo paralelo entre las facultades 
inferiores y las superiores, pues, una imaginación tan viva como la de los niños puede inclinarles hacia la mentira, en este punto Kant sugiere no hacer uso de la fuerza para conseguir la verdad en los niños por medio de castigos, más bien es el momento de hacer uso de la vergüenza. La sociabilidad es el tercer rasgo en la cimentación del carácter. Debe procurarse que el niño conviva y se relacione amistosamente con otros evitando con ello, introversión, la envidia, la vanidad y la extemporaneidad en su desarrollo moral e intelectual ${ }^{24}$.

\section{La Educación Práctica}

La educación práctica o moral. Es aquella mediante la cual se forma el hombre para poder vivir como ser que actúa libremente. Porque práctica es todo aquello que tiene relación con la libertad. Toda educación práctica es una educación para la libertad. Y si seguimos este planteamiento, la libertad como acción práctica, consistiría en no obrar bajo imperativos hipotéticos, es decir, orientados por la necesidad práctica de una acción posible, sí no bajo el imperativo categórico que se orienta por el principio mismo, sin referencia a ningún otro fin.

Así pues, la educación le compete abarcar tres ordenes; primero, la cultura escolar y mecánica-técnica que se refiere al las destrezas y habilidades, siendo entonces didáctica y orientada por el profesor. Esta cultura le otorga poder al hombre para alcanzar todos sus fines y le da un valor en cuanto a sí mismo como individuo. Segundo, de la cultura pragmática, que se relaciona con la prudencia y que lo prepara

${ }^{24}$ Ibídem, págs, 38-43. para la vida pública en su condición de ciudadanos, le otorga un valor social. Tercero, de la formación moral que se refiere al ser moral, le da su valor respecto a su pertenencia con toda la especie humana. En este último orden Kant vuelve a insistir o replicar sobre el propósito de la educación moral: la formación o cimentación del carácter. En su obra Crítica de la Razón Práctica ${ }^{25}$, Kant ya precisaba su concepción acerca de la educación moral y que luego en su obra pedagógica viene a desarrollar en sus recomendaciones para cimentar en los niños la moralidad. Estas recomendaciones van orientadas a presentar a los niños los deberes que deben cumplir, mediante ejemplos y actitudes. Deberes como las obligaciones para consigo mismo y para con los demás. El deber para consigo mismo consiste, en conservar en su propia persona la dignidad humana, por ello la formación del niño debe hacérsele observar que el descuido personal es indecoroso para la humanidad. También con las mentiras que se le permitan al niño en su relación con los demás se coloca a la humanidad muy lejos de su dignidad. Los deberes para con los de-

${ }^{25}$ En la Crítica de la Razón Práctica, Kant precisaba ya su concepción acerca de la educación moral: "No sé por que los educadores de la juventud no se han decidido... a poner en práctica esta tendencia de la razón a ocuparse con placer examinando del modo más sutil las cuestiones prácticas planteadas, $y$, después de haber puesto por fundamento un catecismo puramente moral, no han indagado las biografías de los tiempos antiguos y modernos con el propósito de tener a mano ejemplos para los deberes expuestos, mediante los cuales pusieran a funcionar el juicio de sus alumnos sobre todo a base de comparar acciones semejantes en circunstancias distintas con el objeto de hacer observar su mayor o menor contenido moral...". En: Kant, I. Crítica de la razón práctica. Buenos Aires: Losada, 1961, pág. 161. más como la veneración y el respeto deben ser enseñados a los niños desde muy pronto y se debe tener cuidado en que los ponga en práctica.

Para la recta formación del niño en la moralidad ha de promoverse en las escuelas un catecismo del derecho $^{26}$, con el objetivo de presentar dilemas morales de la vida cotidiana, para que se entrenen en la obligación de hacer lo correcto y el bien, no inclinados por el sentimiento sino por la idea del deber. Con un libro de este género se podría educar a los niños en el conocimiento de los derechos del hombre.

Finalmente Kant es partidario de la educación religiosa pero extraconfesional. La naturaleza de la razón tal como la época ilustrada la caracterizó, rechaza toda religión reveladora. Una Razón Crítica debe considerar dogmático todo acto de fe. Una Razón Interesada no precisa una ayuda sobrenatural para querer que exista un Dios en la tierra. Una Razón Autónoma ve en el Dios revelado una amenaza ${ }^{27}$. Por ello, Kant considera que en cuanto a la relación de la educación de los niños con la religión ha de ser orientada desde el concepto de religión como la ley en nosotros y no fuera y como parte de toda moralidad ${ }^{28}$.

${ }^{26}$ En la Metafísica de las Costumbres, se
vale Kant de un ejemplo para clarificar lo
que promovería en la escuela la educación
de los niños en lo moral, á saber: un cate-
cismo moral. Aquí el maestro pregunta a la
razón de su alumno lo que quiere enseñar-
le, y en el caso de que no sepa responder
a la pregunta, le pone la respuesta en los
labios (guiando su razón). En: Kant, I. Me-
tafísica de las costumbres. Barcelona:
Altaya, 1993, págs. 356-362.
${ }^{27}$ Cortina, A. Etica mínima. Madrid: Tecnos,
1994, pág. 214 .
${ }^{28}$ En su discusión contra el eudemonismo,
Kant produce la tesis central de su filoso- 
Si no se asocia la religión con la moralidad, aquella se reduce a solicitud de favores recibidos, alabanzas, oraciones, servicio supersticioso, temores y una fe de recompensa y castigo, en suma, en el opio para las conciencias y una almohada para dormir placenteramente ${ }^{29}$.

Concluye Kant su tratado pedagógico introduciendo algunas observaciones para los niños que pasan a la adolescencia. La primera, es la diferencia que comienza a establecer entre los sexos, diferencia que se ha de asumir con toda la moralidad posible. Una segunda distinción es el conocimiento de la diferencia de las posiciones y la desigualdad de los hombres. Es importante comenzar a enseñarles, poco a poco, la conciencia de la igualdad de los hombres en la desigualdad civilio.

\section{A manera de conclusión}

Volver a Kant después de Kant en el escenario de una crítica a la razón moderna y en el descrédito de la gran filosofía ${ }^{31}$, parece para la crítica posmoderna un anacronismo y más si nos acercamos a sus reflexiones sobre la educación, escritas en su Tratado de Pedagogía.

fía de la educación, la moralidad. Defiende la idea final de un mundo moral, por una esperanza ética que, además de apelar a la educación como base y trazada con un carácter cosmopolita, abre el horizonte de un tiempo indefinido en clave teológica ya que la idea de Dios sólo tiene sentido en el contexto de la moralidad. Por consiguiente: "es necesario que la moralidad preceda, y la teología la siga: $y$ esto es lo que se llama religión". Kant, I. Tratado de Pedagogía, pág. 54.

29 Ibídem, págs. 53 y 54 .

${ }^{30}$ Ibídem, págs. 55 y 57.

${ }^{31}$ Habermas, J. La Filosofía como vigilante e intérprete. En: Conciencia moral y acción comunicativa. Barcelona: Península, 1998, pág. 11.
Pero, es posible que para algunos Kant sigue siendo Kant. De hecho, y aunque parezca un poco forzado y extraño, para revisar la génesis y evolución de la pedagogía contemporánea debemos retrocedernos hasta Kant. Además la pedagogía es una ciencia reciente surgida en los albores del siglo XIX y que, desde sus orígenes, se vinculó a la filosofía kantiana ${ }^{32}$.

En la reflexión contemporánea y más aún, en la situación actual, en la cual la libertad, la responsabilidad y la moralidad (necesaria para comprender la acción educativa) son evacuadas en términos totalmente empíricos dentro de los límites de una acción instrumental, técnica y estratégica, volver a kant es necesario y relevante, si se piensa todavía que el ser del hombre trasciende los límites de lo meramente empírico o científico ${ }^{33}$. Quizás en las sociedades donde se carece de una razón de lo público y en donde se hace necesario recuperar o construir el ser moral, lo que nos deja la inminencia de nuestra fragilidad, la reputación de Kant aún no palidece. Volver a Kant no para repetirlo sin más en sus ideas absolutas sino para pensar y producir nuestro hoy.

\author{
Rafael Ríos Beltrán \\ Facultad de Educación \\ Universidad de Antioquia
}

\footnotetext{
${ }^{32}$ Estas afirmaciones son hechas por el profesor de la Universidad de Barcelona, Vilanou, T. Conrado. "Sobre la génesis y evolución de la pedagogía contemporánea (a propósito de la herencia kantiana)", En: Revista española de pedagogía. Valencia: Año LVI, No. 210, abril-junio 1998, págs. 245-262.
}

${ }^{33}$ Hoyos, V. Guillermo. "Por un concepto
critico de libertad en la filosofía práctica de
Kant". En: Revista Ideas y Valores. Bogotá: Nos. 66-67, abril (1985), págs. 101-115. 